Trab. Ling. Aplic., Campinas, 45(1): 75-86, Jan./Jun. 2006

\title{
REFLEXÃO INTERATIVA: DESVELANDO E TRANSFORMANDO TEORIAS PRÁTICAS SOBRE O ENSINO DE INGLÊS NA ESCOLA PÚBLICA
}

\author{
ROSANE ROCHA PESSOA \\ Universidade Federal de Goiás
}

\begin{abstract}
RESUMO
Este estudo tem como objetivo investigar as reflexões conduzidas por professores de inglês da escola pública sobre sua prática pedagógica e suas consequiências para os alunos. Os resultados mostraram que os temas principais da reflexão instrução, conteúdo, objetivos, resultados, contexto, professor e alunos. O foco deste trabalho será nas teorias práticas sobre conteúdo e objetos, que não foram simplesmente desvendados mas, printipalmente, questionados e transformados.
\end{abstract}

Palavras-chave: formação de professores; reflexão interativa; ensino de inglês como LE.

\section{ABSTRACT}

This study aimed at investigating the reflections of public school English teachers about their pedagogical practice and its consequences for the students. The results showed that the main themes of reflection were instruction, content, aims, results, context, teacher, and students. The focus of this paper will be on the practical theories about content and aims, which were not simply revealed, but also questioned and transformed.

Key-words: teacher development; reflective interaction; teaching EFL.

\section{INTRODUÇÃO}

Neste estudo, apresento um recorte de minha pesquisa de doutorado (Pessoa, 2002), que objetivou examinar as reflexões de quatro professores de inglês da escola pública sobre sua prática pedagógica e sobre as consequiências dessa prática para os alunos. Os quatro professores foram escolhidos por terem competência tanto lingüística quanto teórica: lingüística, porque são proficientes, e teórica, porque já haviam feito pelo menos um curso de treinamento ou formação além do curso de graduação em Letras. Assim, optou-se por estabelecer uma estrutura de conversa em que o pesquisador interviesse minimamente no processo de reflexão, por acreditar que o professor não é simplesmente alguém que reproduz o conhecimento sobre ensinar e aprender, mas que também é capaz de produzi-lo. E também por entender que a interação de professores pode propiciar o desvelamento, o questionamento e o desenvolvimento desse conhecimento, que será chamado aqui de "teorias práticas". 
PESSOA - Reflexão interativa: desvelando e transformando teorias...

\section{TEORIAS PRÁTICAS DOS PROFESSORES}

“Teorias práticas", "teorias pessoais" ou "teorias implícitas" são alguns dos termos utilizados para designar as sínteses dinâmicas de conhecimentos e crenças a que os professores recorrem ao interpretar o currículo e colocá-lo em prática (Marrero, 1991, apud García, 1999). Neste estudo, optou-se por utilizar o termo “teorias práticas” como o conhecimento acumulado do professor sobre o ato de ensinar (objetivos, procedimentos, estratégias, etc), que serve como base para seu comportamento em sala de aula e para as atividades que utiliza.

No debate atual a respeito do que constituem as teorias educacionais, Britzman (1991, p. 38) considera "o processo de teorização não como uma atividade isolada separada da experiência de ensino ou como uma grande verdade que se tenta impor, mas sim como uma relação vivida, fundamentada na existência prática das pessoas e dependente do processo de interpretação e mudança". Para o autor, as fontes da teoria, "estão na prática, nas vivências dos professores, nas crenças, nas convicções e nos valores profundos representados na prática, no contexto social que envolve tal prática e nas relações sociais que estimulam o encontro ensino e aprendizagem".

Tal visão vai de encontro à concepção tradicional da relação entre teoria e prática no ensino, segundo a qual os professores ensinam, mas não teorizam. No entanto, Zeichner e Liston (1996, p. 38), dois grandes defensores do fato de que os professores produzem conhecimento teórico sobre o ensino, afirmam que

o processo de reflexão, no qual os professores tornam mais conscientes e articulam as teorias práticas implícitas em sua prática e sujeitam-na à crítica, pode ser considerado uma forma de teorização educacional. Esta teorização prática e pessoal oferece uma perspectiva interna sobre o ensino e a aprendizagem nas escolas que não se pode obter por meio de teorias inventadas por estranhos.

Pennycook (1989) e Edge e Richards (1998) salientam que a articulação, pelos professores, do que eles sabem e nas condições estabelecidas por eles próprios é uma forma de validar formas locais de conhecimento. Para Johnson e Freeman (2001), é preciso aceitar publicamente as formas de conhecer dos professores como conhecimento legítimo, que deve ter o mesmo status do conhecimento da disciplina que até hoje dominou o repertório de saberes da formação do professor de segunda língua.

Sobre a relação entre reflexão e conhecimento, Alarcão (1996) argumenta que a reflexão sobre uma ação, uma atitude ou um fenômeno deve ser analisada à luz de referentes que lhe dêem sentido, no caso os saberes já possuídos, frutos da experiência ou da informação, ou os saberes à procura dos quais se lançam por imposição da necessidade de compreender a situação em estudo. O resultado dessa análise é geralmente uma reorganização ou um aprofundamento do conhecimento individual com conseqüências em nível da ação. Segundo Alarcão (1996), é nessa interação que reside a essência da relação teoria e prática no mundo profissional dos professores.

\footnotetext{
Esta e as outras citações, originalmente em inglês, foram traduzidas para facilitar a leitura.
} 
Também Van Lier (1994, p. 7) defende o fim da separação entre teoria e prática e o estabelecimento de uma nova e dinâmica inter-relação entre teoria, prática e pesquisa, pois a prática deve ser vista não só como "uma oportunidade para fazer pesquisa", mas também como "uma fonte de teoria". Ele acrescenta que, em vez de a situação de ensino e aprendizagem ser tratada como um sistema ordenado e governado por regras a serem descobertas e relações simples de causa e efeito, ela deve ser vista como um "complexo sistema adaptável" (Van Lier, 1994, p. 7), que tem padrões e regularidades, mas também irregularidades, e cujo efeito é de difícil previsão. Tal complexidade exige que se focalize no detalhe ou, como diria Van Manem (1991), no "momento pedagógico". Para Van Lier (1994, p. 8), "a teoria da prática, então, começa com um exame escrupuloso dos detalhes da interação ensino e aprendizagem e com um monitoramento rígido dos efeitos resultantes das mudanças implementadas".

Uma forma de fazer com que as teorias práticas sejam mobilizadas e aceitas como válidas é encorajar o conhecimento profissional partilhado dos professores, que é, segundo Nóvoa (1997, p. 26), "o único processo que pode conduzir a uma 'transformação de perspectiva' (Mezirow, 1990) e a uma produção pelos próprios professores de saberes reflexivos e pertinentes". Vários são os teóricos (Solomon, 1987; Van Lier, 1994; Ur, 1996; Oprandy, Golden e Shiomi,1999; Zeichner 2001) que salientam a importância das conversas entre professores como atividades poderosas para expor e desenvolver o conhecimento pedagógico e para consolidar saberes emergentes da prática profissional.

Oprandy, Golden e Shiomi (1999) apresentam outras vantagens de conversas em grupo sobre as dinâmicas de aulas: desenvolver uma cumplicidade entre os professores; propiciar uma percepção mais aguçada da própria prática; possibilitar que eles descubram novas formas de ver o contexto da sala de aula; perceber as possibilidades de mudança; incentivar o senso de profissionalismo que pode não existir antes de trabalhar cooperativamente; e, finalmente, desenvolver a capacidade de interpretação dos professores, levando-os à reflexão crítica.

As formas de interação entre professores têm sido objeto de estudo tanto na área da Educação quanto na de Lingüística Aplicada e abrangem desde as conversas de professores - também denominadas "conversação" (conversation) (Yonemura, 1982), "conversas" (talk) (Waite, 1993), "conversa cooperativa" (co-operative talk), "conversas colaborativas" (collaborative conversations) (Oprandy, Golden e Shiomi, 1999), "processo de reflexão conjunta" (joint reflective process) ou "conversas reflexivas" (Telles, 1996), "sessões reflexivas" (Magalhães, 2002) etc. - sobre a prática pedagógica até a realização de estudos sistemáticos, com ou sem a participação de pesquisadores. As conversas entre professores são vistas como bastante positivas, pois podem fazer com que os professores se desvencilhem das formas instintivas de atuação, prestem atenção nas consequiências de suas ações, gerem alternativas e tornem-se cada vez mais conscientes das possibilidades educacionais de sua prática. Assinale-se que, apesar de os termos "conversas" e "conversação" serem mais comumente usados na literatura, optou-se por utilizar "reflexão", para evitar o vínculo com as conversas triviais que são realizadas cotidianamente, e "interativa", em vez de "colaborativa", tendo em vista a intenção de não intervir nas reflexões e também pela 
PESSOA - Reflexão interativa: desvelando e transformando teorias...

impossibilidade de definir de antemão que papéis os participantes iriam assumir nas sessões de reflexão.

\section{METODOLOGIA}

Dentre os vários dados obtidos, três se transformaram nos dados primários da pesquisa: oito sessões de reflexão interativa sobre aulas de $5^{\mathrm{a}}$ série dos quatro professores (estimuladas por gravações em vídeo); uma sessão de reflexão interativa sobre os resultados do processo de ensino, realizado ao final do primeiro semestre letivo de 2000 (os dados desses resultados foram coletados através de entrevistas em inglês, com seis alunos de três professores, e de uma atividade de leitura da quarta professora que, como não havia focalizado as habilidades orais, não achava que seus alunos estavam preparados para uma entrevista. As atividades foram realizadas pela pesquisadora, mas a partir da orientação dos professores); e, finalmente, a entrevista final, realizada seis meses após a realização da pesquisa.

Como resultado das sessões de reflexão interativa, foram mobilizadas, questionadas e transformadas teorias práticas sobre os seguintes domínios do conhecimento pedagógico: procedimentos pedagógicos, conteúdo, objetivos, resultados, contexto, professor e alunos. Destes, serão aqui focalizados apenas dois - conteúdo e objetivos -, que se apresentam natural e coerentemente inter-relacionados nos depoimentos dos professores. Para preservar sua identidade, os seguintes codinomes foram utilizados: Ana Clara, Pedro Henrique, Márcia e Jonas. Como a análise focaliza o conteúdo das reflexões e não a sua forma lingüística exata, as transcrições foram adaptadas à norma padrão. Os códigos presentes neste recorte foram baseados em Van Lier (1988, p. 243-244): termo sublinhado $\rightarrow$ ênfase; [...] $\rightarrow$ trecho suprimido; e [ ] $\rightarrow$ comentário da pesquisadora.

\section{TEORIAS PRÁTICAS MOBILIZADAS}

Os dois temas - conteúdo e objetivos do ensino de inglês na escola pública - surgiram na primeira sessão de reflexão da aula de Ana Clara. Sua aula objetivou trabalhar as habilidades orais e dividiu-se em quatro estágios: aquecimento, apresentação, prática e produção. Márcia foi quem introduziu o tópico central de reflexão com a pergunta: "Qual seria o objetivo de ensinar inglês para a $5^{a}$ série?". Basicamente, duas teorias práticas foram mobilizadas. De um lado, estão Márcia, Jonas e Pedro Henrique, que defendem o foco na leitura, já que a necessidade dos alunos brasileiros é ler e não falar, embora não descartem o trabalho com as habilidades orais, e, de outro, Ana Clara, que faz a defesa do foco nas habilidades orais: "acho mais do que justo você ter uma aula de língua estrangeira, na qual você possa praticar as quatro habilidades. [...] O professor tem a obrigação de dar essa oportunidade aos alunos, porque eles gostam e querem falar inglês". 
Na segunda sessão de reflexão, uma discussão sobre temas é desencadeada, pelo fato de Pedro Henrique não ter trabalhado um tema do projeto da escola em sua aula. Sua explicação é que temas como "violência" são difíceis de ser trabalhados. Duas teorias práticas são desveladas nesta sessão. Como resultado de diferentes experiências de formação, Márcia e Jonas acreditam que os temas devem ser o elemento central de suas aulas e que a maneira mais natural de trabalhá-los é por meio da leitura. Para Márcia, o ensino de inglês "tem que partir de algum tema, porque senão a aula fica vazia" e, para Jonas, o trabalho com temas é até mesmo uma forma de compensar os resultados nem sempre positivos no que se refere à aprendizagem da língua. Ele afirma que alguns aprendem, "mas infelizmente a maioria parece que não consegue sair falando: 'Oh, my name is fulana, I'm from Brazil...". E argumenta que trabalhando "família", por exemplo, "pelo menos alguma coisa fica, às vezes melhora o relacionamento do filho em casa com o pai".

Na terceira sessão de reflexão, sobre a aula de Jonas, o tópico "temas" volta a ser discutido, porque Ana Clara afirma que "tanto faz utilizar um livro ou trabalhar com temas, que a frustração em termos de língua é sempre a mesma". Para Jonas, o aluno "não vai aprender tudo, mas alguma coisa ele tem que aprender: ele tem que saber falar sobre ele, tem que saber falar sobre a família dele, sobre as coisas que ele gosta, sobre o país, sobre a cidade, em inglês. [...]. [Mas], pelas condições de trabalho, pela quantidade de aluno e o número de aulas, o aluno não vai aprender a falar e a ouvir, não vai sair falando inglês. Se você estiver pensando assim, você vai ficar frustrada". Aqui, despontam dois pontos de vistas diversos, de Jonas e Márcia, que trabalham com temas. Enquanto Jonas defende o desenvolvimento da habilidade oral, ainda que o objetivo não seja a proficiência, Márcia enfatiza a aquisição da língua por meio da leitura, embora não descarte totalmente o desenvolvimento das habilidades orais.

Na quinta sessão, a segunda aula de Ana Clara é objeto de reflexão. Sua aula é sobre países e nacionalidades e objetiva que os alunos usem "Where are you from?" e "I'm from...”. Para Márcia, essa é uma “aula vazia”, em que o professor não “ajuda os meninos a crescer". Ela coloca para o grupo a seguinte pergunta: "Qual é a nossa função como professor de inglês? Será que é só ensinar inglês? Só ensinar palavra em inglês?" Ela acredita que a formação do aluno só pode se efetivar por meio da discussão de textos. Já Jonas pensa que a língua e os temas devem ser trabalhados. Aqui, percebem-se claramente duas teorias práticas, uma - de Márcia - que enfatiza a leitura como a habilidade mais útil para o aluno em todas as séries do ensino fundamental, porque inclusive pode contemplar aspectos educacionais, e outra - de Pedro Henrique e Jonas - que privilegia as habilidades orais como base para o trabalho com temas.

A oitava sessão tem como objeto de reflexão a aula de Márcia, na qual um texto em inglês sobre o Parque das Emas foi trabalhado: primeiramente, o tema foi discutido em português, depois eles buscaram as palavras cognatas e, em seguida, a professora escreveu no quadro as idéias do texto em português. Jonas é quem levanta uma questão novamente voltada ao conteúdo: “os objetivos de língua inglesa, havia algum?” Pedro Henrique acha que Márcia deveria ter apresentado e praticado o vocabulário em inglês antes de dar o texto. A teoria que se constrói aqui é que é possível "trabalhar temas dentro da língua 
PESSOA - Reflexão interativa: desvelando e transformando teorias...

inglesa", de Pedro Henrique e Jonas. Essa aula leva Ana Clara a reafirmar sua teoria de que "no caso do ensino de inglês no nível fundamental, vale a pena trabalhar outras habilidades também", mas ela começa a rever sua concepção, na medida em que reconhece a importância do trabalho com temas, porque os alunos têm pouco conhecimento geral. Nesse momento, uma outra teoria é construída por Pedro Henrique e Jonas: a ênfase na leitura e na escrita vale sobretudo para as $7^{\text {as }}$ e $8^{\text {as }}$ séries porque, nas $5^{\text {as }}$ e $6^{\text {as }}$ séries, a ênfase deve ser dada às habilidades orais, visto que os alunos querem falar. Para eles, essa é uma forma de primeiro os alunos se familiarizarem com estruturas básicas da língua, que lhes auxiliarão nas atividades de leitura. No entanto, ela é rejeitada por Márcia, o que se pode perceber na seguinte afirmação: "Você não precisa da gramática para você ler o texto". Entretanto, uma teoria consensual dos quatro professores se delineia nessa sessão: o desenvolvimento das habilidades lingüísticas deve estar aliado ao trabalho com temas, e estes devem problematizar questões vivenciadas no mundo social, como o respeito ao meio ambiente.

Nas reflexões sobre esse tópico, parecem óbvias a influência dos PCN sobre Jonas e Márcia e a orientação de Ana Clara e Pedro Henrique mais voltada à abordagem comunicativa, o que é reflexo não só de sua experiência como alunos, mas também de sua formação e experiência profissionais. Em um continuum, tem-se Ana Clara, à esquerda, a favor da ênfase nas habilidades orais, e, à direita, Márcia, em defesa do foco na leitura. Pedro Henrique estaria mais próximo de Ana Clara, ao passo que Jonas estaria mais próximo de Márcia. Um ponto consensual entre eles é que o grande entrave ao desenvolvimento das quatro habilidades são os fatores contextuais e que o foco na leitura tem como vantagem a substituição da gramática pelo texto.

\section{TEORIAS PRÁTICAS QUESTIONADAS}

A nona sessão de reflexão, voltada para os resultados do processo de ensino e aprendizagem, foi o momento em que os quatro professores mais questionaram as próprias teorias práticas sobre o conteúdo e os objetivos, pois apenas um aluno de Ana Clara usou a língua de forma comunicativa e os alunos de Márcia, apesar de terem conseguido ler um texto sozinhos demonstraram, na entrevista, ter desenvolvido pouco conhecimento sobre os temas trabalhados pela escola. A questão levantada por Ana Clara é: "Como é que a gente pode atingir a realidade desse aluno? Ou seja, trazer coisas para ele que façam sentido e que ele se sinta motivado a conhecer mais para transformar mesmo?".

Márcia, que em quase todas as sessões de reflexão defendera a leitura como prioridade nas aulas de língua estrangeira, afirma:

Quando eu comecei esse trabalho de leitura, eu pensava no vestibular, e para isso as minhas aulas vão estar ajudando, e ajudam também no processo de escrita tanto de língua inglesa quanto de língua materna. Mas eu acho difícil falar que escrita é mais importante que a oralidade. Eu acho que depende do objetivo deles, e o objetivo dos alunos é mais falar inglês. [...]. Eu acho que minha aula é falha na questão da oralidade, que eu tenho que tentar trabalhar com eles. [...] As quatro habilidades têm a mesma importância. 
Jonas e Pedro Henrique, que priorizam as habilidades orais, dão os seguintes depoimentos:

Jonas: [...], será que é importante aprender a falar "My name's fulano, I'm from..., Good morning!", cantar uma musiquinha ali, cantar outra música aqui. É complicado ensinar inglês para a classe [social] que a gente ensina.

Pedro Henrique: Eu fico analisando, será que se eu tivesse trabalhado mais texto e produção escrita, será que eles não teriam fixado mais?

Pedro Henrique mostra-se intrigado com essa questão das habilidades orais: "Às vezes, fica tão mecânico que você fala assim, 'What's your name? Repeat! What's your name? What's your name?' Aí se você fala assim, 'My name’s Pedro Henrique', eles não vão falar 'My name's Ricardo', porque eu falei 'My name's Pedro Henrique'”. Ressalte-se a dificuldade do professor em trabalhar a oralidade, pois ele percebe a ineficácia da repetição mecânica, mas parece não saber o que fazer para que o aluno tenha uma produção espontânea.

Para Jonas, os temas não são a resposta para o ensino da escola pública, mas apenas o início. Ele e Márcia se contrapõem ao conteúdo que Ur (1996) chama de "trivial", caracterizado por eventos e personagens neutros e tópicos superficiais. Entretanto, por outro lado, uma pergunta de Márcia, “como trabalhar temas na língua inglesa?”, permanece sem resposta.

Percebe-se, então, que os quatro professores colocam em xeque suas teorias práticas sobre o conteúdo e os objetivos do ensino de inglês na escola pública e, mesmo não tendo respostas para os questionamentos levantados, acenam para uma mudança na prática, que de fato é constatada na última entrevista da pesquisa.

\section{TEORIAS PRÁTICAS TRANSFORMADAS}

Nas entrevistas finais, realizadas um semestre após o término da coleta de dados, pôde-se perceber que os professores redimensionaram suas teorias práticas a respeito do conteúdo e objetivos do ensino de inglês da escola pública. Ana Clara, que centrava seu trabalho nas habilidades orais, como única abordagem possível, passa a reconhecer que o desenvolvimento das habilidades de leitura é uma alternativa viável, dependendo de quem são os alunos, de quais são suas expectativas em relação à língua e de quais são as condições contextuais:

Nesta escola, eu encontrei três $5^{\text {as }}$ séries totalmente diferentes. Uma $5^{\text {a }}$ série é a dos mais novos, eles são adolescentes, são hiperativos e vão para escola porque querem algo mais do inglês do que simplesmente ler e escrever. E tem uma turma daqueles mais problemáticos, sempre é assim, que realmente a aula não rende muito [...]. É um pouco mais difícil lidar com eles, você tem que pedir silêncio, as atividades não têm aquele rendimento que você tem nas outras. E tem a turma dos mais 
PESSOA - Reflexão interativa: desvelando e transformando teorias...

velhos, pessoas com mais de quarenta anos, é uma turma mais lenta [...], alguns com dificuldade de aprendizagem. Então, eu comecei a trabalhar de uma maneira diferente.

Ela também começou a reconhecer a importância da formação do aluno e do trabalho com temas, haja vista os alunos terem pouco conhecimento de mundo. O depoimento seguinte mostra que ela passou a acreditar que, para algumas turmas, o conhecimento de mundo deve mesmo suplantar o desenvolvimento lingüístico:

[...] eu percebi que realmente inglês para essas turmas do noturno, essas turmas que têm muita dificuldade, $o$ inglês serve como pano de fundo. Na verdade, o que trabalhei mesmo com eles foram conhecimentos gerais, que iam ajudá-los na geografia, no português, na história, quem foi George Washington, o que foi a independência dos Estados Unidos.

Segundo Ana Clara, nessas turmas ela passou a trabalhar estratégias de leitura, como palavras cognatas, linguagem não-verbal, conhecimento prévio etc., com resultados positivos: "A gente fechou o ano muito bem". E, se antes Ana Clara criticava os projetos, ela passou a perceber sua validade. Embora a escola onde trabalha agora seja seriada e não trabalhe com projetos, ela afirma: "Eu não sei se eles [os professores da escola] querem fazer projeto, [mas] eu faço [...]. Eu gostei muito da idéia que aprendi com Márcia, Pedro Henrique e Jonas e acho que vale a pena trabalhar assim".

Essa última fala e o depoimento de Ana Clara, de modo geral, permitem concluir que o enfoque na leitura passou a ser o fundamento de suas aulas, ao passo que a oralidade agora é trabalhada quando os alunos mostram interesse e capacidade para desenvolvê-la: "Eu acho que eu consegui um equilíbrio entre as quatro habilidades, de acordo com o que eles dão conta mesmo".

Pedro Henrique mencionou como efeito das sessões de reflexão sobre sua prática pedagógica o fato de ter superado sua dificuldade em trabalhar com textos: "Com a Márcia, eu pude perceber que é fácil trabalhar texto". Além disso, hoje, ele não vê problemas na tradução de alguns itens lingüísticos que possam facilitar a leitura para o aluno: "Aprendi como a gente pode trabalhar tradução, porque, até então [...], eu pensava que era proibido trabalhar tradução em sala, mas, na verdade, não é". Essa aprendizagem de como lidar com textos em sala de aula incentivou Pedro Henrique a realizar, no ano que seguiu ao da pesquisa, um projeto com livros paradidáticos, porque agora ele afirma sentir-se preparado para fazê-lo.

Um outro efeito, em nível de conteúdo, foi que a produção de textos passou a fazer parte de sua prática pedagógica: “[...], ele [Jonas] gosta de criar textos e eu aprendi a criar textos também. Inclusive eu criei um texto muito interessante, 'Where are you from', e foi interessante". Ainda com Jonas, Pedro Henrique diz ter confirmado sua concepção sobre a relevância das atividades com música realizadas em sala de aula.

Para Pedro Henrique, as sessões de reflexão também foram importantes para que ele tivesse reforçada sua concepção sobre oralidade, como se pode ver a seguir: "A Ana Clara me ensinou muito a questão da oralidade, porque ela gosta de trabalhar isso. Isso aí foi um suporte para mim, porque eu gosto muito de trabalhar com diálogos, entrevistas". 
Também para Jonas as sessões de reflexão conjunta foram fecundas no sentido de alterar alguns aspectos importantes de sua prática pedagógica, apesar de suas aulas terem sido avaliadas positivamente pelos outros três professores. Para ele, as sessões foram muito importantes para uma reavaliação de sua prática, que estava muito centrada em temas e projetos:

Eu estava muito influenciado pelo curso que eu tinha feito em São Paulo, com uma doutora lá da PUC, [nome da doutora], e ela falava que as aulas de inglês, não só de inglês, mas que as aulas tinham que ser centradas em projetos, em temas, que o conteúdo [lingüístico] não importa, que a gramática não importa, que não precisa ter uma seqüência gramatical para o aluno aprender.

Jonas avalia que ainda não se desvencilhou totalmente dessas idéias, tanto que depois das sessões de reflexão, ele continuou a trabalhar temas. No entanto, observa que passou "a mostrar a estrutura da língua para o aluno" e vai continuar fazendo isso, após verificar que seus alunos estavam "meio perdidos na língua propriamente dita. Às vezes, a gente discutia um tema, o tema ficava muito bem discutido, mas estava faltando o inglês, aquela aula de inglês mesmo". Segundo ele, o que vai fazer daí por diante é trabalhar a língua com temas, mas também com "uma certa seqüência gramatical, para ter uma lógica na cabeça do aluno".

As sessões reflexivas permitiram-lhe também verificar que, com a discussão dos temas, o inglês estava ficando de lado, e que, então, ele passou "a falar mais inglês em sala", a fazer "drills", prática que ele já vinha realizando nas $5^{\text {as }}$ séries, mas que estendeu a todas as outras séries do ensino fundamental. Em uma conversa que teve com os alunos no final do semestre, ele mencionou que pôde constatar que tal prática vai ao encontro do que os alunos querem, que é "experimentar a língua". Na opinião de Jonas, essa foi a mudança mais importante advinda das sessões de reflexão.

Márcia foi a que demonstrou ter sofrido menos influência. Entretanto, considerandose que seu conhecimento sobre o ensino de leitura tinha sido bem consolidado por várias experiências, tais como sua formação universitária, o trabalho realizado na iniciação científica e o estudo dos PCNs de língua estrangeira, as sessões de reflexão foram muito significativas, no sentido de questionar esse conhecimento. De certo modo, suas teorias práticas já haviam sido colocadas em xeque pelos resultados de uma pesquisa que realizara em um curso de especialização.

Apesar de, em todas as sessões, Márcia ter defendido o enfoque na leitura para todas as séries do ensino fundamental, ela manifestou o reconhecimento de que sua prática pedagógica era limitada: "Eu estava muito centrada no texto", e o convencimento de que as habilidades orais devem ser desenvolvidas nas escolas da rede pública. Assim, ela mencionou que, no semestre subseqüente ao da pesquisa, tentou fazer atividades orais, mas que a tarefa não foi fácil: "Eu tentei fazer essas atividades com as Ds, que seriam as $3^{\text {as }}$ séries, porque são turmas mais fáceis para fazer esse trabalho. [Mas], com turmas como as Es [4 ${ }^{\text {as }}$ séries], que você nem chegou a conhecer, que são as turmas piores da escola, então é muito difícil você fazer esse trabalho". 
PESSOA - Reflexão interativa: desvelando e transformando teorias...

Desse modo, ela justifica que desenvolve as habilidades orais nas turmas mais fáceis, e os alunos têm feito diálogos, têm conversado mais e "está dando certo". E que não faz esse trabalho nas turmas em que há um número excessivo de alunos ou problemas de disciplina pois, segundo Márcia, são poucos os alunos que realmente fazem as atividades quando trabalham em pares ou grupos.

Apesar disso, Márcia afirma que não abriu mão de sua concepção no que diz respeito à formação do aluno e que, para isso, é preciso usar textos: “[...] Para a escola pública, eu acho que o texto ajuda muito mais a formar o aluno. [...]. Mas eu acho também que não pode ser só isso. Tem que ir além disso também. E é por isso que eu tento fazer as atividades orais, eu tento fazer as atividades de listening também. Então eu acho que envolveria as quatro [habilidades]".

E Márcia aponta que o desenvolvimento da comunicação oral vai ao encontro do desejo dos alunos: "Quando você dá uma atividade oral, eles realmente querem falar, a classe se envolve, e quando você dá diálogo, eles vêm, conversam com você e conversam com outro colega. A fala para eles é muito importante, eles querem falar, sim".

Márcia, nessa entrevista final, argumenta ainda que sua pesquisa de monografia já havia the mostrado que os alunos querem falar. E que até a realização das sessões de reflexão, ela "estava tentando fazer alguma coisa, mas não estava conseguindo". Nesse sentido, ela diz: "[...], as aulas de Pedro Henrique me marcaram muito. [...]. Eu tinha dúvida de como eu ia fazer isso [trabalhar as habilidades orais]. Para mim, essa era a grande questão depois da minha pesquisa. Aí depois eu vi como ele estava fazendo isso".

Para Márcia, portanto, assistir à gravação das aulas foi tão importante quanto refletir interativamente sobre elas, na medida em que essa atividade permitiu-lhe aprender como se estrutura uma aula em que se pratica a oralidade. No entanto, ela ainda procura respostas para a sugestão, presente nos PCN, de que as habilidades orais sejam desenvolvidas a partir dos textos: "Eu fico pensando em como fazer isso. É aquela crítica que eu fiz: então, quer dizer que falar [inglês] é [dizer] 'Hi, how are you?'? [...] Porque não é só isso. Existem várias formas de você falar várias coisas em inglês".

O desejo de Márcia é propor atividades orais que não se restrinjam aos diálogos que servem simplesmente para interagir socialmente, como cumprimentar, perguntar o nome, perguntar de onde é etc., mas ainda não sabe como fazê-lo. Esse é o grande desafio colocado para Márcia, como resultado das reflexões.

\section{CONSIDERAÇÕES FINAIS}

Neste estudo, procurou-se mostrar o desenvolvimento das teorias práticas de quatro professores de inglês da escola pública sobre dois domínios do conhecimento pedagógico: conteúdo e objetivos, que foram dois dos tópicos mais discutidos em nove sessões de reflexão, nas quais os professores tiveram oportunidade de refletir interativamente sobre suas práticas pedagógicas, sem qualquer agenda determinada pela pesquisadora. 
Trab.Ling.Aplic., Campinas, 45(1) - Jan./Jun. 2006

Ao longo das sessões de reflexão, várias teorias práticas sobre os dois tópicos foram sendo mobilizadas e questionadas a partir das aulas assistidas em vídeo, que nos remetem, por exemplo, a teóricos como Pennycook (1988, p. 29), para quem o ensino de inglês como língua estrangeira deve superar a visão "a-política e a-histórica" de linguagem, compreendida como um sistema "para transmissão de mensagem ou para fazer coisas com as palavras", e passar a concebê-la como "um sistema de significação de idéias que desempenha um papel fundamental no modo como significamos o mundo e a nós mesmos". Para o autor, isto significa romper com uma concepção "meramente funcional da linguagem" e a sua conseqüente "trivialização do conteúdo", preocupação bastante freqüente nos depoimentos de Márcia.

No entanto, as reflexões refletem especialmente a polêmica hoje existente entre lingüistas aplicados brasileiros ligados à área de ensino de línguas estrangeiras, a respeito das habilidades que devem ser enfatizadas nas aulas de línguas estrangeiras no contexto da escola pública, tais como: Devem-se ensinar as quatro habilidades? Deve-se focalizar a habilidade de leitura aliada ao trabalho com temas transversais?

Com relação a essas duas questões, dois pontos foram consensuais. O primeiro é o de que as quatro habilidades devem ser ensinadas, porque os alunos querem e têm o direito de aprender a falar inglês na escola pública; e o segundo é o de que a formação é fundamental para esses alunos e, nesse sentido, temas e textos devem ser trabalhados. Todavia, uma pergunta ainda se coloca: como aliar a formação dos alunos ao ensino das quatro habilidades? Pois como é que o aluno iniciante pode discutir, na língua inglesa, temas que podem contribuir para a sua formação? Será que ele não precisa primeiramente de uma base lingüística, que inevitavelmente se construirá por meio de um conteúdo trivial, como "What's your name? What do you like? What did you do yesterday? Have you ever been to Pirenópolis?", para depois poder discutir sobre "violência", por exemplo? Uma sugestão de Jonas e Pedro Henrique se delineia: nas $5^{\text {as }}$ e $6^{\text {as }}$ séries, a ênfase deve ser dada às habilidades orais e, nas $7^{\text {as }}$ e $8^{\text {as }}$ séries, à leitura e à escrita, mas não é um consenso entre o grupo, de modo que fica a questão colocada para todos os professores das escolas regulares que querem começar a ter controle sobre suas decisões pedagógicas, a influir na estruturação do currículo com que trabalham e a trilhar o caminho de uma maior autonomia profissional.

Em suma, este estudo mostrou como a reflexão interativa pode ser um instrumento poderoso para que os professores possam compreender e transformar as suas teorias práticas, mas, mais importante que isso, para que eles possam deixar de ser objetos de pesquisa e se tornar sujeitos do conhecimento.

\section{REFERÊNCIAS BIBLIOGRÁFICAS}

ALARCÃO, I. (1996). Ser professor reflexivo. In: ALARCÃO, I. (Org.). Formação reflexiva de professores: estratégias de supervisão. Porto: Porto. p. 171-189.

BRITZMAN, D. (1991). Practice makes practice: a critical study of learning to teach. Albany: Sunny Press. 
PESSOA - Reflexão interativa: desvelando e transformando teorias...

EDGE, J.; RICHARDS, K. (1998). May I see your warrant, please?: justifying outcomes in qualitative research. Applied Linguistics. Oxford University Press, v. 19, n. 3, p. 334-356.

GARCÍA, C. M. (1999). Formação de professores: para uma mudança educativa. Porto: Porto.

JOHNSON, K. E.; FREEMAN, D. (2001). Teacher learning in second language teacher education: a sociallysituated perspective. Revista Brasileira de Lingüística Aplicada. Belo Horizonte, v. 1, n. 1, p. 53-69.

MAGALHÃES, M. C. C. (2002). O professor de línguas como pesquisador de sua ação: a pesquisa colaborativa. In: GIMENEZ, T. (Org.). Trajetórias na formação de professores de línguas. Londrina: UEL. p. 39-58.

NÓVOA, A. (1997). formação de professores e profissão docente. In: NÓVOA, A. (Coord.). Os professores e sua formação. Lisboa: Dom Quixote. p. 13-33.

OPRANDY, R. with GOLDEN, L.; SHIOMI, K. (1999). Language teaching awareness: a guide to exploring beliefs and practices. Cambridge: Cambridge University Press.

PENNYCOOK, A. (1989). The concept of method, interested knowledge, and the politics of language teaching. TESOL Quarterly, v. 23, n. 4, p. 589-618.

. (1998). A Lingüística Aplicada dos anos 90: em defesa de uma abordagem crítica. In: SIGNORINI, I.; CAVALCANTI, M. C. (Orgs.). Lingüística Aplicada e transdisciplinaridade: questões e perspectivas. Campinas: Mercado de Letras, p. 23-49.

PESSOA, R. R. (2002). A reflexão interativa como instrumento de desenvolvimento profissional: um estudo com professores de inglês da escola pública. Belo Horizonte. Tese (Doutorado) - Programa de Pós-Graduação em Letras/Estudos Lingüísticos, Universidade Federal de Minas Gerais.

SOLOMON, J. (1987). New thoughts on teacher education. Oxford Review of Education, v. 3, n. 13, p. 267-274.

TELLES, J. A. (1996). Being a language teacher: stories of critical reflection on language and pedagogy. Toronto. (Doctoral Dissertation) - Graduate Department of Education, University of Toronto.

UR, P. (1996). A course in language teaching: practice and theory. Cambridge: Cambridge University Press.

VAN LIER, L. (1988). The classroom and the language learner. New York: Longman.

VAN LIER, L. (1994). Some features of a theory of practice. TESOL Journal, v. 4, n. 1, p. 6-10.

VAN MANEN, M. (1977). Linking ways of knowing with ways of being practical. Curriculum Inquiry, n. 6, p. 205-228.

WAITE, D. (1993). Teachers in conference: a qualitative study of teacher-supervisor face-to-face interactions. American Educational Journal, v. 30, n. 4, p. 675-702.

YONEMURA, M. (1982). Teacher conversations: a potential source of their own professional growth. Curriculum Inquiry, v. 12, n. 3, p. 239-256.

ZEICHNER, K. M. (2001). Educating reflective teachers for learner-centered education: possibilities and contradictions. In: ENCONTRO NACIONAL DE PROFESSORES UNIVERSITÁRIOS DE LÍNGUA INGLESA, 16. Londrina: Universidade de Londrina.

ZEICHNER, K. M.; LISTON, D. P. (1996). Reflective teaching: an introduction. New Jersey: Lawrence Erlbaum Associates. 